\title{
Environmental Monitoring and Simulation of Infrasound Generating Mechanism of Traffic Flow
}

\author{
Marina Vladimirovna Grafkina', Boris Nikolaevich Nyunin', \\ Evgeniya Yurevna Sviridova ${ }^{1 *}$ \\ 1 Moscow Polytechnic University, Bolshaya Semenovskaya, 38, Moscow, 107023, Russia \\ * Corresponding author's e'mail: evg_sviridova@mail.ru
}

\begin{abstract}
Ground vehicles are the main sources of noise and infrasounds in residential areas. Numerous published works are devoted to the studies of audible sound, its sources in vehicle, and development of measures to its reduction. The authors believe that the problem of infrasound occurrence and propagation in residential areas and - hence - its negative impact on humans and ambient environment is underestimated. Development of predictions and experimental methods of studying the infrasound generating mechanism and environmental monitoring of this negative factor are an urgent issue. A significant portion of acoustic emission from a vehicle comprises infrasound and low frequency range. Internal and external infrasound of vehicle were measured. A prediction model was proposed and the influence of vehicle design features on the infrasound level was estimated. Predictions of the external infrasound generating the mechanism of vehicles reveal that its frequency and level depend on driving speed, drag coefficient, vehicle body length, and Strouhal number Wheels, which execute rotation and progressive movement in airstream, are important sources of vehicle infrasound. Five wheel harmonics were calculated for motor vehicles at various driving speeds, the existing dependences are detected. It was demonstrated that the regulatory levels of infrasound can be exceeded only in residential areas adjacent to traffic flow with driving speeds higher than $80 \mathrm{~km} / \mathrm{h}$. The results of field studies of infrasound level on the streets of Moscow were presented. Recommendations on the development of environmental monitoring and main approaches to reduce infrasound in urban environment were given.
\end{abstract}

Keywords: infrasound, ground vehicles, environmental monitoring, infrasound pressure, shedding of vortices, drag coefficient, wheel harmonics, driving speed.

\section{INTRODUCTION}

Infrasound is a negative environmental factor. In urban environment, motor transport is the main source of noise and infrasound. Despite the scheduled reduction of noise from traffic flows in audio range, the infrasound level of vehicles under certain conditions does not decrease but can even increase, which exerts negative impact on the properties of urban environment.

The external sound field of a vehicle is determined by the following constituents: engine, gas exchange system (exhaust system and air injection system for fuel combustion), transmission units (gearbox, drive axles), tires upon interaction with road dressing, aerodynamic noise (interaction between vehicle body and air flow).
Infrasound is a component of the aerodynamic noise and the noise of tire rolling.

Infrasound and low frequency noise exert negative impact on humans. It imposes general biological reaction: headache, dizziness, violation of functions of vestibular apparatus, impaired concertation and workability, feeling of fear, general discomfort [Zinkin et al. 2012; Mikhailov, Boldyrev 2011; Long et al. 2013; Hensel et al. 2007; Francis 2007].

Numerous available studies are devoted to the audible noise and development of measures on its reduction [Trifonov, Roslyakova 2018; Vasil'ev 2015; Berdyshev, Shevchenko 2014; Enembe 2018; Cai et al. 2019; von Graevenitz 2018]. Fewer investigations are devoted to the environmental 
monitoring of infrasound in residential areas adjacent to highways [Vasil'ev 2011].

The issue of negative infrasound impact is still valid upon conversion to electric cars and elimination of the main source of vehicle noise, i.e. internal combustion engine, since the main source of infrasound is airstream.

On the basis of the aforementioned and own projects in this field [Grafkina et al. 2015; Grafkina et al. 2018], the authors believe that in order to develop efficient tools of infrasound reduction from ground vehicles, it would be reasonable to study the infrasound generating mechanism of various vehicles and environmental monitoring in residential areas.

\section{METHODS}

The studies performed on a vehicle scaled model in Institute of mechanics (Moscow State University) revealed that the external infrasound in frequency band of $1.7-28 \mathrm{~Hz}$ could be generated by pulsations of longitudinal component of airstream speed. This leads to the formation of vortex noise related with periodical shedding of vortices from bypassed body, frequency of shedding of vortices is equal to that of sound.

Aerodynamic noise is subdivided into vortex noise, roller noise, noise of heterogeneous flow, noise of impact waves, noise of self-excited gas dynamic pulsations.

The vortex noise is subdivided into the noise of periodically shed vortices, noise of turbulent bypassing, noise of turbulent jet. Vortex noise is a wide range of aerodynamic noises related with vortex generation. This vortex generation can be chaotic or regular. In the first case, the turbulent wake is generated where air pulsates chaotically, and in the second case the Karman street is generated after bypassed body comprised of large checker-wise eddies.

Frequency of shedding of vortices and, respectively, the frequency of generated noise is determined by the Strouhal number:

$$
f=S_{h} \cdot \frac{V}{D}
$$

where: $S_{h}$ is the Strouhal number;

$V$ is the speed, $\mathrm{m} / \mathrm{s}$;

$D$ is the characteristic size, $\mathrm{m}$.
The constant $S_{h}$ is the similarity criterion upon generation of vortex noise. It was established that the Strouhal number can vary in certain limits as a function of Reynolds number Re.

$$
\mathrm{Re}=\frac{U d}{v}
$$

where: $d$ is the cylinder diameter, $\mathrm{m}$;

$U$ is the flow speed, $\mathrm{m} / \mathrm{s}$;

$v$ is the kinematic viscosity, $\mathrm{m}^{2} / \mathrm{s}$.

The infrasound pressure $(P)$ can be predicted as follows:

$$
P=\frac{\rho}{c^{3}}\left(C_{x} S h\right)^{2} V^{6} l^{2}
$$

where: $C_{x}$ is the drag coefficient;

$l$ is the cylinder length, $\mathrm{m}$;

$c$ is the speed of sound, $\mathrm{m} / \mathrm{s}$;

The influence of vehicle design features on the infrasound level was theoretically studied using a qualitative model: cylinder in airstream. The cylinder sizes correspond to the vehicle dimensions and the drag corresponds to that of vehicle $\left(C_{x}\right)$.

The airstream speed $(V n)$ equals to the vehicle speed $(\mathrm{Va})$ (Fig. 1). The cylinder diameter $(D)$ equals to the height of vehicle body $(h)$.

Wheels, which execute rotation and progressive movement in airstream are important sources of vehicle infrasound.

At low and medium vehicle speeds, the first wheel harmonic $f_{\text {wheel }}$ is exposed mainly in infrasound range of noise spectrum (below $20 \mathrm{~Hz}$ ); only at high speeds of modern passenger cars $(115-120 \mathrm{~km} / \mathrm{h})$ this harmonic can be heard in audio frequency band. As a rule, it is characterized by the highest intensity and at certain speed ranges it can stipulate high level of internal and external infrasound.

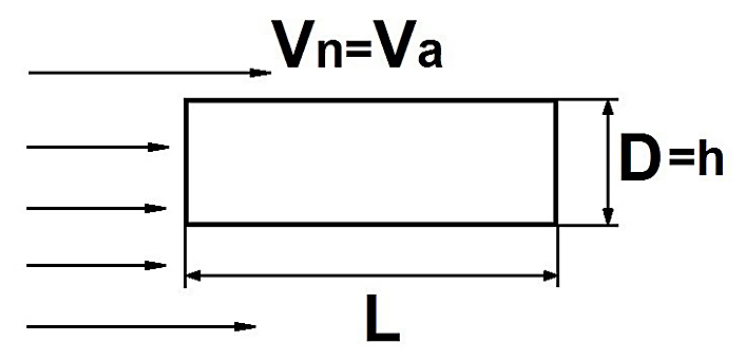

Figure 1. Model of infrasound generation 
The frequency of wheel harmonic in the vibration spectra of units and noise in vehicle body is:

$$
f=k \cdot V_{a} / 22,6 R_{d y n}
$$

where: $k=1,2,3 \ldots$ is the numerical series;

$V_{a}$ is the vehicle speed, $\mathrm{m} / \mathrm{s}$;

$R_{d y n}^{a}$ is the dynamic roller radius, $\mathrm{m}$.

\section{RESULTS}

Let us consider the influence of elasticity of air volume on the infrasound level in a vehicle. This was aided by the vibration measurement of roof, floor, infrasound level and vertical flow of acoustic power at fully open and closed windows as well as at various degree of opening of rear door.

Figure 2 illustrates the infrasound spectra on rear seat with open and closed windows at driving speed of $60 \mathrm{~km} / \mathrm{h}$. It can be seen that open windows reduce the infrasound level by $8-10 \mathrm{~dB}$ in the frequency band of 9-13 Hz.

However, in the case of only one fully or partially open window, the situation is reversed.

Partial or full opening of only one window leads to an increase in the infrasound level from $2 \mathrm{~dB}$ to $10 \mathrm{~dB}$ depending of the extent of window opening in the frequency band of 2-20 Hz. An increase in the infrasound level can be explained considering the vehicle body as a Helmholtz resonator.

Infrasound in passenger compartment can be excited (as in Helmholtz resonator) as a consequence of pressure pulsation in the airstream from open window.
Resonant frequencies were calculated for vehicle upon opening of rear door window by $1 / 10$, $1 / 2$ and at fully open window, the eigenfrequency of vehicle body as a resonator was $7 \mathrm{~Hz}, 13 \mathrm{~Hz}$, and $18 \mathrm{~Hz}$, respectively. Exactly in this frequency band, a maximum increase occurs in infrasound upon variation of window opening rate. The calculations of coherence function between vertical oscillations of front wheels, floor, roof, and infrasound pressure in passenger compartment at fully open window also confirm the assumption about infrasound excitation by airstream. The rate of interrelation between these oscillating processes and infrasound decreased upon the window opening from 1 to $0.4-0.6$ in the frequency band of 10-13 Hz. Such a decrease in the coherence function upon opening of one window indicates the occurrence of a new excitation source. Most probably, it is airstream, pressure pulsations from open window excite infrasound oscillations (similar to Helmholtz resonator) in the passenger compartment.

In order to obtain a more complete understanding of the infrasound generated by passenger cars, the external noise was measured. Figure 3 illustrates the average spectra of vehicle external noise in the frequency range of $2-20 \mathrm{~Hz}$ at the driving speed of 100 and $120 \mathrm{~km} / \mathrm{h}$. The width of the analyzed band is $\mathrm{F}=1 \mathrm{~Hz}$. The maximum infrasound level takes place at $2 \mathrm{~Hz}$ and equals 94-97 dB, depending on the driving speed. With frequency increase, it drops from $6 \mathrm{~Hz}$ by about $7 \mathrm{~dB}$ per octave, and then it remains nearly steady; at $10-12 \mathrm{~Hz}$, the infrasound level is $\sim 85 \mathrm{~dB}$.

The levels of external infrasound were estimated on various vehicle types (bus, lorry, light commercial vehicle, hybrid passenger car, and urban minicar). The calculations were performed

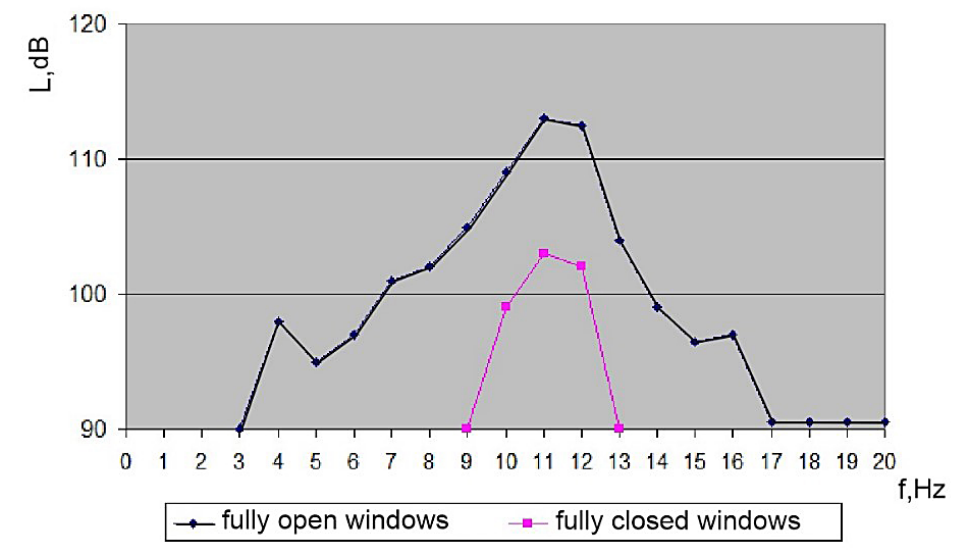

Figure 2. Noise spectrum in vehicle passenger compartment at driving speed of $60 \mathrm{~km} / \mathrm{h}$ 


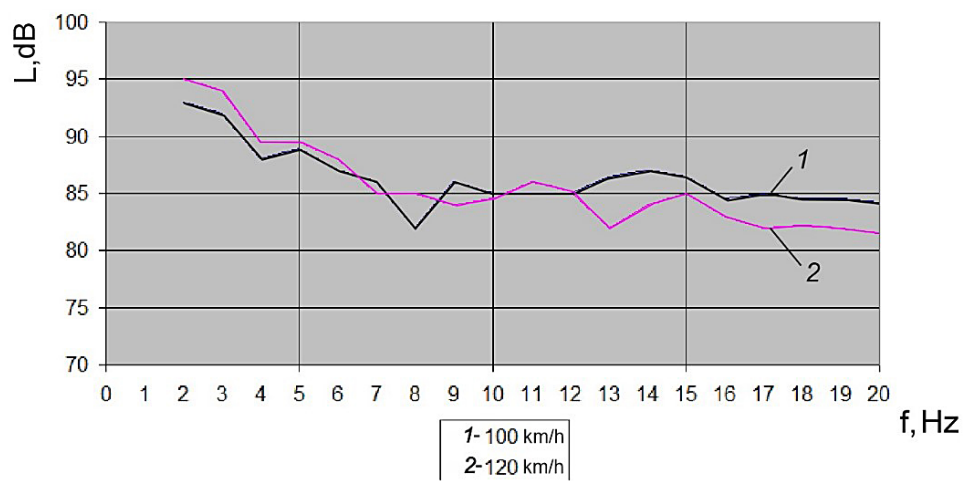

Figure 3. Spectrum of vehicle external noise during driving

for each vehicle at driving speed of 60, 80, 100, and $120 \mathrm{~km} / \mathrm{h}$. Table 1 summarizes the specifications of the considered vehicles.

Frequency calculations pertaining to shedding of vortices demonstrated that the frequency band of external infrasound was from 1 to $5 \mathrm{~Hz}$.

Infrasound pressure was estimated by Eq. (3), where $\rho$ was the air density, $\rho=1.29 \mathrm{~kg} / \mathrm{m}^{3} ; c$ was the speed of sound, $c=340 \mathrm{~m} / \mathrm{s} ; S_{h}=0.2 ; C_{x}$ and $l$ were selected from Table 1 for each vehicle.

The calculations demonstrated that the infrasound levels were in the range from 65 to $135 \mathrm{~dB}$ depending on the driving speed and vehicle type. The maximum levels of external infrasound took place upon the movement of lorries and buses.

The minimum level of external infrasound was generated by Toyota Prius and Daewoo Matiz. Then, the model was applied for estimation of influence of vehicle design features on the infrasound level. The minimum length of vehicle body was that of Daewoo Matiz; hence, the influence of vehicle length on the infrasound level was theoretically estimated for this model. The vehicle body length varied from 3.5 to $12 \mathrm{~m}$.

Table 1. Vehicle specifications

\begin{tabular}{|l|c|c|c|}
\hline Vehicle & $\begin{array}{c}\text { Drag } \\
\text { coefficient } \\
C_{x}\end{array}$ & $\begin{array}{c}\text { Vehicle length } \\
\text { I, m }\end{array}$ & $\begin{array}{c}\text { Passenger } \\
\text { compartment } \\
\text { height } h, \mathrm{~m}\end{array}$ \\
\hline Ikarus 250 & 0.71 & 12 & 3.2 \\
\hline $\begin{array}{l}\text { KamAZ } \\
5320\end{array}$ & 0.68 & 7.39 & 2.83 \\
\hline $\begin{array}{l}\text { GAZ } \\
33022\end{array}$ & 0.65 & 5.47 & 2.57 \\
\hline $\begin{array}{l}\text { Renault } \\
\text { Logan }\end{array}$ & 0.36 & 4.29 & 1.53 \\
\hline $\begin{array}{l}\text { Toyota } \\
\text { Prius }\end{array}$ & 0.26 & 4.46 & 1.5 \\
\hline $\begin{array}{l}\text { Daewoo } \\
\text { Matiz }\end{array}$ & 0.39 & 3.49 & 1.48 \\
\hline
\end{tabular}

Figure 4 illustrates the infrasound level as a function of vehicle length. It can be seen that with the increase in the vehicle length by 2 times, the level of external infrasound increases by $10 \mathrm{~dB}$, and with the increase in the vehicle length to $12 \mathrm{~m}$, the level of external infrasound increases by $22 \mathrm{~dB}$.

The influence of $C_{x}$ on the infrasound level was estimated on Toyota Prius because this vehicle was characterized by minimum drag coefficient $C_{x}=0.26$.

Figure 5 illustrates the external infrasound as a function of drag coefficient. When $C_{x}$ varies from 0.26 to 1 , the infrasound level increases by $35 \mathrm{~dB}$.

Figure 6 illustrates the infrasound level as a function of Strouhal number $\left(S_{h}\right)$.

Therefore, the predictions demonstrated a significant dependence of the external infrasound pressure on the design features of vehicle body or cabin.

Five harmonics were predicted for wheel of $R=13$ inches of passenger car at driving speed of 80,100 , and $120 \mathrm{~km} / \mathrm{h}$. The predictions are summarized in Table 2.

At $80-120 \mathrm{~km} / \mathrm{h}$ the frequencies of wheel harmonics are in the range of $20-170 \mathrm{~Hz}$. With the increase in the wheel radius, the frequencies of wheel harmonics will decrease, especially for lorries and buses.

In traffic flow, the spectrum of wheel harmonics will overlap low frequency and infrasound range.

Experimental studies on ground vehicle infrasound were carried out in Moscow at the Bolshaya Semenovskaya street and Staraya Basmannaya street.

The studies revealed that the levels of infrasound pressure in the overall frequency band were from 55 to $85 \mathrm{~dB}$, i.e. corresponded to preset 


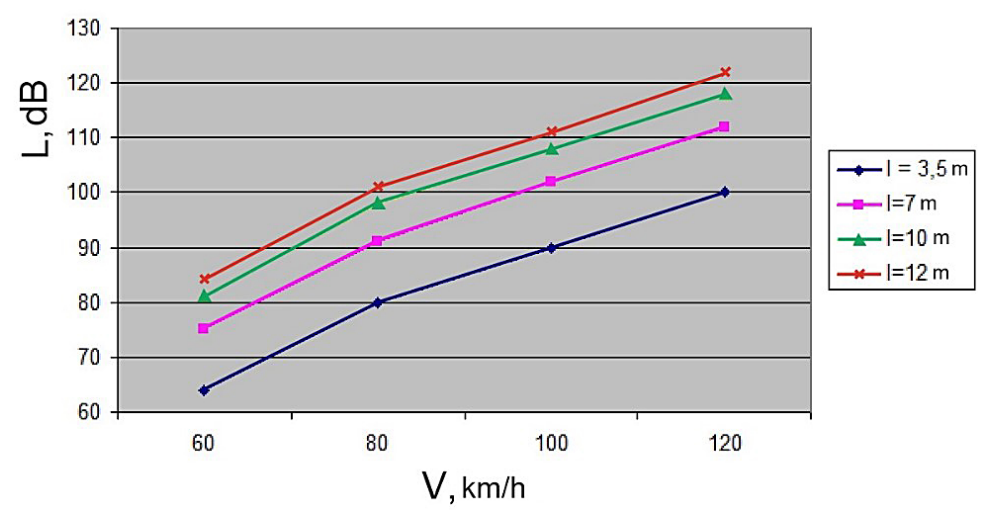

Figure 4. Predicted infrasound level at various vehicle length

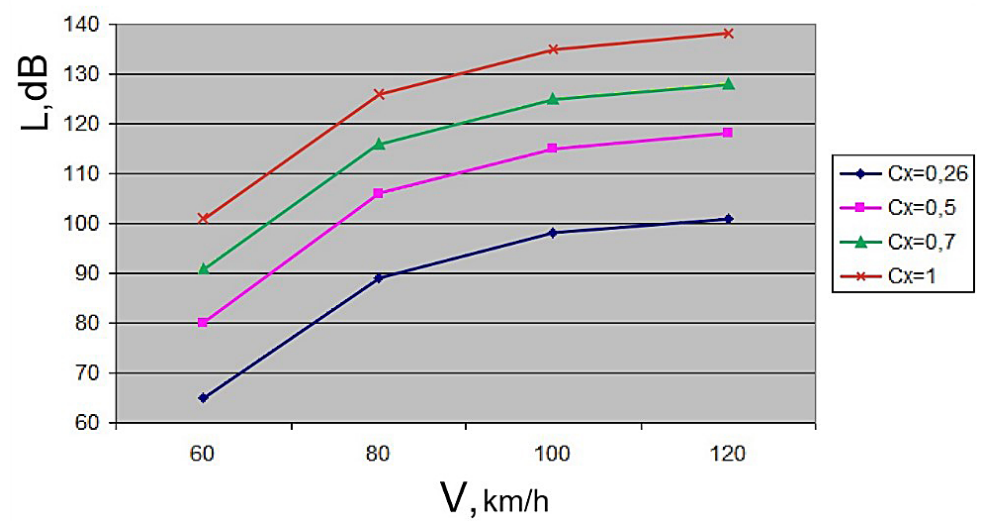

Figure 5. Predicted level of external infrasound at various drag coefficients

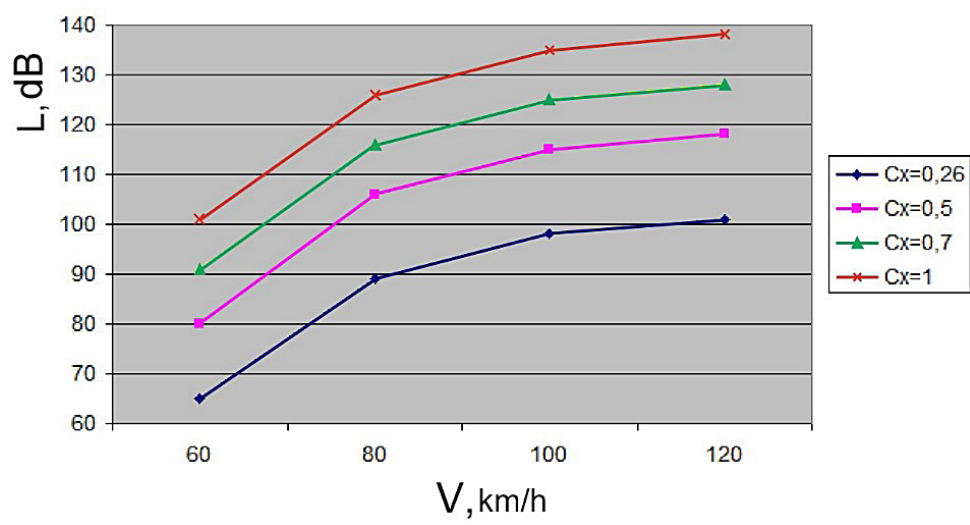

Figure 6. Predicted infrasound level as a function of Strouhal number

regulatory values [Sanitary regulations and norms 1996] except for $16 \mathrm{~Hz}$ when the infrasound level exceeded the norms by $1.5 \mathrm{~dB}$. This agrees well with simulation predictions which demonstrated that at $40-60 \mathrm{~km} / \mathrm{h}$, the infrasound levels did not exceed $90 \mathrm{~dB}$, i.e. met the requirements.

Figures 7-8 illustrate the measured infrasound level and low frequency noise on Staraya Basmannaya street.
Environmental estimation demonstrates that in all octave bands the infrasound level conforms to the regulations. Theoretical predictions evidence that the infrasound level strongly depends on the vehicle driving speed. Two traffic lights installed on Staraya Basmannaya street reduce the speed of traffic flow to $40-50 \mathrm{~km} / \mathrm{h}$. For these speeds, the infrasound level of lorries and buses does not exceed $90 \mathrm{~dB}$, and of passenger cars -70 
Table 2. Predicted frequencies of wheel harmonics

\begin{tabular}{|c|c|c|c|c|c|}
\hline$V[\mathrm{~km} / \mathrm{h}]$ & $f_{1}[\mathrm{~Hz}]$ & $f_{2}[\mathrm{~Hz}]$ & $f_{3}[\mathrm{~Hz}]$ & $f_{4}[\mathrm{~Hz}]$ & $f_{5}[\mathrm{~Hz}]$ \\
\hline 80 & 22 & 45 & 67 & 90 & 112 \\
\hline 100 & 28 & 56 & 84 & 112 & 141 \\
\hline 120 & 33 & 67 & 101 & 135 & 169 \\
\hline
\end{tabular}

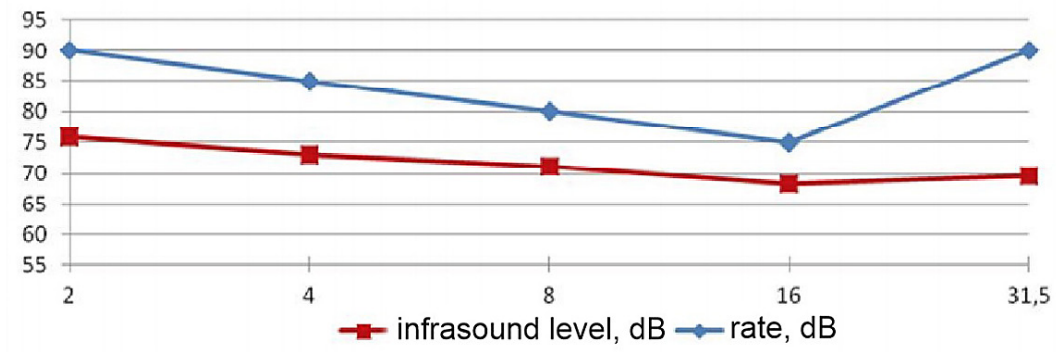

Figure 7. Infrasound levels at the distance of $7.5 \mathrm{~m}$ from the road

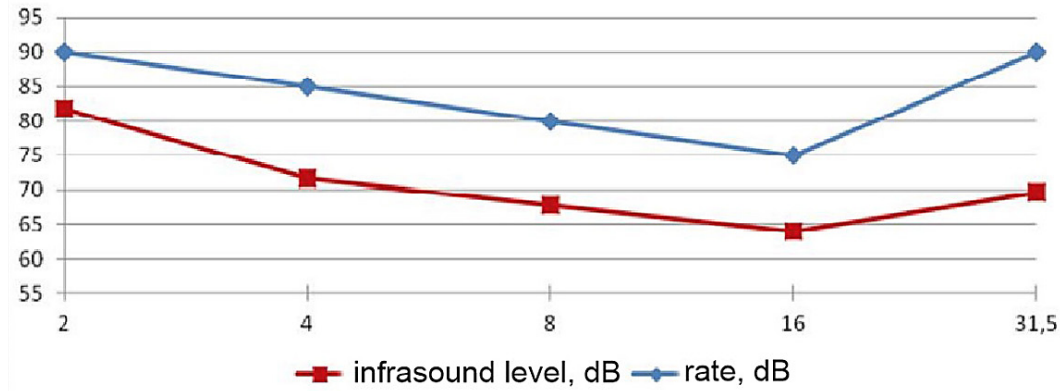

Figure 8. Infrasound levels at the distance of $15 \mathrm{~m}$ from the road

dB. It should be expected that in the area of the 3rd Moscow Inner Ring Road, where the vehicle speeds are significantly higher, the infrasound level will exceed the regulatory values.

\section{DISCUSSION}

At present, the recommendations on reduction of traffic noise have been developed for audiorange.

There are two known approaches to reduce the noise of vehicles. The first approach stipulates the development of vehicle engineering in the field of reducing noise generated by vehicle mechanisms, systems, and units, of tire industry in the field of reducing noise of tire rolling, fabrication of road concrete mixes in the field of development of noise reducing grades and arrangement of road dressing. The second approach is based on the use of noise barriers, noise control glazing, sound absorbing materials on facades. The noise levels can be reduced to $16 \mathrm{~dB}$ by noise barriers and to $30 \mathrm{~dB}$ by noise control glazing.
The performed theoretical and experimental studies using the proposed acoustic (qualitative) model of the external infrasound generation by vehicle body and studies on the infrasound pollution of residential areas revealed that the preset regulatory values were exceeded in the residential areas adjacent to highways with permissible speed limit of $80 \mathrm{~km} / \mathrm{h}$ and higher.

The authors propose the following recommendations on the reduction of infrasound level in residential areas:

1. At the stage of vehicle designing, it is necessary to develop the measuring procedure and norm of maximum permissible levels of infrasound and to certify vehicles as the main source of infrasound in residential areas.

2. Developing a procedure for prediction monitoring of expected infrasound level of urban traffic flow with consideration for its structure (number of passenger cars, lorries, and other vehicles) and speed mode.

3. Developing a monitoring procedure of infrasound level in residential areas in the vicinity of highways and railroads. 
4. Developing urban planning measures considering the detected areas of negative impact of infrasound.

5. It is recommended to use infrasound reflection silencers for the fabrication of noise barriers.

\section{CONCLUSION}

1. A prediction research of the external infrasound generating mechanism revealed that its frequency and level depended on driving speed, drag coefficient, vehicle body length, and Strouhal number. The frequency band of vehicle external infrasound is in the range from 1 to $5 \mathrm{~Hz}$. The maximum levels of external infrasound take place upon the traffic of vehicles and buses, and the minimum levels are upon the traffic of minicars. When the vehicle body length increases twice, the level of external infrasound increases by 10 $\mathrm{dB}$, and when the body length increases by four times - by $22 \mathrm{~dB}$. When the drag coefficient increases from 0.26 to 1 , the infrasound level is raised by $35 \mathrm{~dB}$. The infrasound level increases with the Strouhal number.

2. A prediction research of the external infrasound generating mechanism revealed that its frequency and level depended on driving speed, drag coefficient, vehicle body length, and Strouhal number. The frequency band of vehicle external infrasound is in the range from 1 to $5 \mathrm{~Hz}$. The maximum levels of external infrasound take place upon the traffic of vehicles and buses, and the minimum levels are upon the traffic of minicars. When the vehicle body length increases twice, the level of external infrasound increases by 10 $\mathrm{dB}$, and when the body length increases by four times - by $22 \mathrm{~dB}$. When the drag coefficient increases from 0.26 to 1 , the infrasound level is raised by $35 \mathrm{~dB}$. The infrasound level increases with the Strouhal number.

3. Environmental estimation of the field results in urban environment enables to assume that the infrasound level can exceed the regulatory values upon traffic flow higher than $80 \mathrm{~km} / \mathrm{h}$. Hence, reasonable traffic arrangement would allow to reduce the infrasound levels and to decrease negative impact of this factor on human organism and environment.
4. External infrasound in the frequency band of $1.7-28 \mathrm{~Hz}$ can be generated by pulsations of longitudinal component of airstream speed.

5. Infrasound generation of ground vehicles is related with periodic shedding of vortices from the bypassed object, the frequency of shedding of vortices is equal to that of sound.

6 The authors believe that it is required to develop a schedule of environmental monitoring of infrasound of ground vehicles. The acquired results of infrasound monitoring would allow developing efficient means of reducing the levels of this negative factor (reflection silencers, active noise silencers, and others).

\section{REFERENCES}

1. Berdyshev O.V., Shevchenko A.E. 2014. Vliyanie shuma na organizm cheloveka. Profilaktika shuma [Noise influence on human organism. Noise prevention]. Vestnik Permskogo natsional'nogo issledovatel'skogo politekhnicheskogo universiteta. Bezopasnost' i upravlenie riskami, 1, 42-51.

2. Cai M., Lan Z., Zhang Z., Wang H. 2019. Evaluation of road traffic noise exposure based on high-resolution population distribution and grid-level noise data. Building and Environment, 147, 211-220.

3. Enembe O. 2018. Okokon, Tarja Yli-Tuomi, Anu W. Turunen, Pekka Tiittanen, Timo Lanki Traffic noise, noise annoyance and psychotropic medication use. Environment International, 119, 287-294.

4. Francis A. 2007. Duck Medical and non-medical protection standards for ultrasound and infrasound. Progress in Biophysics and Molecular Biology, 93(1-3), 176-191.

5. Grafkina M.V., Nyunin B.N., Sviridova E.Y. 2015. Development of ecological monitoring system of environmental energy pollution. International Journal of Applied Engineering Research, 18, 38733-38740.

6. Grafkina M.V., Nyunin B.N., Sviridova E.Y. 2018. Nauchno-prakticheskie rekomendatsii po snizheniyu negativnogo vozdeistviya avtotransportnykh potokov na selitebnye territorii [Theoretical and practical recommendations on reduction of negative impacts of traffic flow on residential areas ]. Ekologiya urbanizirovannykh territorii, 1, 58-64.

7. Hensel J., Scholz G., Hurttig U., Mrowinski D., Janssen T. 2007. Impact of infrasound on the human cochlea. Hearing Research, 233(1-2), 67-76.

8. Long H, Zheng L., Gomes F.C., Zhang J., Yuan H. 2013. Study on osteogenesis promoted by low sound pressure level infrasound in vivo and some 
underlying mechanisms. Environmental Toxicology and Pharmacology, 36(2), 437-442.

9. Mikhailov D.V., Boldyrev D.A. 2011. Vozdeistvie infrazvuka na cheloveka [Infrasound impact on humans]. Proceedings, 5(3), 39-40.

10. Sanitary regulations and norms $2.2 .4 / 2.1 .8 .10-35-$ 2002 (1996) Infrasound on working places, in residential and public spaces, as well as in residential areas. Retrieved January 18, 2019 from: http://docs. cntd.ru/document/1200029239.

11. Trifonov A.P., Roslyakova L.I. 2018. Shumy i mery bor'by s shumom, vibratsiei [Noises and protection against noise and vibration]. In: Gorokhov A.A. (Eds.) Problems and challenges of development in Russia: A glimpse into the future by young people. Proceedings, All-Russian Scientific Conference (in 4 volumes), 78-81.

12. Vasil'ev A.V. 2011. Monitoring i snizhenie negativnogo vozdeistviya nizkochastotnogo zvuka i vibratsii na territorii gorodskogo okruga Tol'yatti [Monitoring and reduction of negative impact of low frequency sound and vibration in Togliatti municipal district]. In Protection of inhabitants against increased noise impact: All-Russian Scientific Conference (St Petersburg, March 22-24, 2011), St Petersburg, 149-164.

13. Vasil'ev A.V. 2015. Snizhenie nizkochastotnogo shuma avtomobil'nykh DVS s ispol'zovaniem glushitelei shuma [Reduction of low frequency noise of vehicle ICE using silencers]. In: The 7th Lukanin Readings. Solution of environmental issues in vehicle complex. Proceedings, 7-8.

14. von Graevenitz K. 2018. The amenity cost of road noise. Journal of Environmental Economics and Management, 90, 1-22.

15. Zinkin V.N, Bogomolov A.V., Dragan S.P., Akhmetzyanov I.M. 2012. Kumulyativnye mediko-ekologicheskie effekty sochetannogo deistviya shuma i infrazvuka [Cumulative medical and environmental effects of combined action of noise and infrasound]. Ekologiya i promyshlennost' Rossii, March, 46-49. 